This is a self-archived version of an original article. This version may differ from the original in pagination and typographic details.

Author(s): Wang, Haichao; Lahdelma, Risto; Salminen, Pekka

Title: Stochastic multicriteria evaluation of district heating systems considering the uncertainties

Year: 2018

Version: Accepted version (Final draft)

Copyright: (c) 2018 ASHRAE

Rights: In Copyright

Rights url: http://rightsstatements.org/page//nC/1.0/?language=en

Please cite the original version:

Wang, H., Lahdelma, R., \& Salminen, P. (2018). Stochastic multicriteria evaluation of district heating systems considering the uncertainties. Science and Technology for the Built Environment, 24(8), 830-838. https://doi.org/10.1080/23744731.2018.1457399 


\section{Stochastic multicriteria evaluation of district heating systems considering the uncertainties}

\section{Haichao Wang, Risto Lahdelma \& Pekka Salminen}

To cite this article: Haichao Wang, Risto Lahdelma \& Pekka Salminen (2018): Stochastic multicriteria evaluation of district heating systems considering the uncertainties, Science and Technology for the Built Environment, DOI: 10.1080/23744731.2018.1457399

To link to this article: https://doi.org/10.1080/23744731.2018.1457399

Accepted author version posted online: 27 Mar 2018.

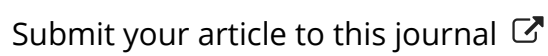

Q View related articles $\llbracket$

View Crossmark data $₫$ 
Publisher: Taylor \& Francis

Journal: Science and Technology for the Built Environment

DOI: https://doi.org/10.1080/23744731.2018.1457399

\section{Stochastic multicriteria evaluation of district heating systems considering the uncertainties}

Haichao Wang, $\mathrm{PhD}^{1,2, *}$, Risto Lahdelma, $\mathrm{PhD}^{3}$, and Pekka Salminen, Professor ${ }^{4}$

${ }^{1}$ Dalian University of Technology, Dalian, 116024 China

${ }^{2}$ Aalto-yliopisto Insinooritieteiden korkeakoulu, Aalto, 00076 Finland

${ }^{3}$ Aalto University, Espoo, Finland

${ }^{4}$ Jyvaskylan Yliopisto, Jyvaskyla, 40014 Finland

*Corresponding author email: haichaowang@dlut.edu.cn

It is of great importance to choose a suitable district heating (DH) system for a specific DH area from the economics, environment and energy (3E) points of vie $\mathrm{T}$. This is a multicriteria decision making problem, in which the criteria performance values (PVs) and weighting are characterized by uncertain or imprecise information. In this study, seven candidate $\mathrm{DH}$ systems are evaluated from the viewpoints of $3 \mathrm{E}$ by the stochastic multicriteria acceptability anaiysis (SMAA) method. SMAA is able to handle the uncertainties of the criteria PVs and the weighting at the same time. These uncertainties are very common and typical in reallife, but in most cases are not treated judiciously or just neglected. In this paper, we propose to use a Probability Distribution Function (PDF), a Monte Carlo simulation in combination with the concept of Feasible Weight Space (FWS) to handle the uncertainties. The model is demonstrated in a case study in China and the resuits show that the proposed method is capable to give more reliable and flexible results when the unsertainuies are considered.

Keywords

Stochastic, Multicriteria evaluation, District heating (DH), Uncertainty. 


\section{Introduction}

District heating $(\mathrm{DH})$ system is one of the basic city infrastructures in cold climate areas. In China, $\mathrm{DH}$ was initially used in 1950s but developed very slowly afterwards. However since 1990s, DH grew much faster and it was reported that the DH area expanded from about 250 million square meters to more than 2600 million square meters during year 1991 and 2006 (Huang, 2011). In the past ten years, since China has been undergoing a fast urbanization, the total DH demand was growing even faster. For example at the end of year 2012, the total DH production of China was over 20000PJ, and the productien inserement per year is about 2000PJ.

Combined heat and power (CHP), heat only boiler (HOB) and heat puinps (HPs) are the most popular heat sources in China to satisfy the huge amount of heat demand According to Tsinghua University building energy research center (2014), coal-fired heat only boiler supplies approximately $48 \%$ of the district heat, followed by the CHP that produces about $42 \%$ of district heat. Gas-fired heat only boiler takes the third place with a contribution of nearly $8 \%$; but the share from other heating technologies including heat pump is very small and less than 2\%. In China, CHP planis are mainly coal-based and almost a half of the total heat is produced by coal-fired HOB. This is mainly because coal is the primary fuel for DH because of the connatural energy structure of China (Lin, 2002). Due to the increase of quality of life in China, more and more DH systems will be built in the near future, and the DH area will be gradually expanded from north China to south Cnina, specifically from the extremely cold area and cold area to the hot summer and cold winter area, as linulicated in Fig. 1.

Differenc $D H$ technologies have different characteristics from the economics, environment and energy (3E) points or view; therefore it is a very important task for the decision makers (DMs) and managers to choose the most suitable DH system for a specific area (Cao, 2002). Moreover, the evaluation of DH systems is not a single objective problem, on the contrary, it is a typical multicriteria decision analysis (MCDA) problem, and the use of MCDA method in Heating ventilating and air conditioning (HVAC) systems are of more 
importance (Jiang et al., 2007). It can help the DMs make more consistent decisions by considering all important factors, which often include conflicting criteria and usually have some uncertainties (Troldborg et al., 2014; Shan et al., 2013; Gang et al., 2015).

In this paper, seven popular DH systems (Wei et al., 2010) which were investigated before in China are evaluated again with more emphases on the uncertainties in criteria performance values (PVs) and the weighting. These DH systems cover a wide range of technologies, which are based on: 1) coal-fired CHP; 2) gas-fired HOB; 3) oil-fired HOB; 4) coal-fired HOB; 5) solar energy HP; 6) water source heat pımp (WSHP); and 7) ground source heat pump (GSHP). Most of the data for these DH systerns are based on the real-life existing DH installations.

Some previous studies have been carried out to develop multicriceria evaluation methods for choosing the optimal DH systems or heating technologies from the standpcints of technology, economy, and environment. Ghafghazi et al. (2010) have done a multicriteria evaluation for choosing the energy sources of a DH system in Vancouver, Canada, possible energy sources are naturai gas, wood pellets, sewer heat, and geothermal heat. The evaluation criteria are: GHG emissions, particulate matter emissions, maturity of technology, traffic load, and local source. Kontu et al. (2015) carried but a multicriteria evaluation of heating systems including renewable energies for a sustainable residential area in southern Finland. In their study, eleven alternative heating systems were evaluated in terms of fifteen criteria. The Stochastic Multicriteria Acceptability Analysis (SMAA) method was used to analyze this problem. The problem was analyzed in two phases first without the preference information from citizens and then with the weighting information. The results show that district heating produced by biomass based CHP is the most widely acceptable heating alternative followed by ground source heat pump both with and without preference information. But the study did not take into account of the uncertainty in weighting. Soltero et al. (2016) developed a framework to evaluate the potertial for natural gas cogeneration in Spain. The evaluation was implemented by environmental, economic and regulatory analyses at four levels including national, regional, municipality and district, using a proposed top-down and bottom-up methodology. Li et al. (2015) evaluated the CCHP systems for hotels, offices and 
residential buildings in Dalian (China) from energetic analysis, economic operation and environment effect viewpoints. They use fuzzy optimum selection theory to evaluate the integrated performances of CCHP systems with various operation strategies but the uncertainties in weighting process is not well defined and considered. The abovementioned methods worked well in the application-oriented case studies, but it could be better if uncertainties in criteria and weighting were better considered in their studies.

In general, different kinds of uncertainties in criteria PVs and in subjective judgments (Zarghami and Szidarovszky, 2009; Durbach and Stewart, 2012) as well as policy and technology uncertainties (Tylock et al., 2012) are very common and thus should be treated carefully. Therefore, in th is stucy the objective is to develop a novel and efficient multicriteria evaluation method, which cain simultaneously consider the uncertainties in the criteria PVs and weighting for the DH systems. We adopt the Stochastic Multicriteria Acceptability Analysis (SMAA) model to evaluate the DH systems, because it can handle the uncertainties by using a Probability Distribution Function (PDF) and a Monte Carlo simulation (wang and Haves, 2014). Moreover, we also propose to use the 'Feasible Weight Space' (FWS) instead of a deterministic weight vector in MCDA, because the weights should indicate all DMs preference information (wang et al., 2015). FWS is a union of all weight vectors obtained from $\mathrm{OMs}$ judgment matrices.

This study develops a more efficient method to the multicriteria decision analysis of heating, ventilating and air conditioning systems, and to solve the problems of the uncertainties in criteria PVs and weighting in a more judicious manner. This paper is organized as following. Firstly, the SMAA model and FWS concept as well as the way to handle the uncertainties are introduced; followed by a case study in China, where the developed inethocis are demonstrated with seven candidate $\mathrm{DH}$ systems; then the proposed method is compared with a fuzzy comprehensive evaluation method (Wei et al., 2010); finally the conclusion is drawn according to the results and discussion of the study.

\section{Methods}


SMAA is a family of models that encompasses many different variants (Tervonen and Figueira, 2008). This paper proposes to use SMAA-2 and SMAA-O models to solve the multicriteria decision making problems that have both quantitative and qualitative criteria (Lahdelma et al., 2001).

\subsection{The SMAA-2 model}

Let's take an MCDA problem, which has $m$ alternatives $A=\left\{x_{1}, x_{2}, x_{3}, \ldots, x_{m}\right\}$ and $n$ criteria. SMAA-2 model assumes that DM's preference can be expressed by a utility function defined as, $u_{(}\left(x_{i}, w\right)$, which calculates the utility value for alternative $x_{i}$ when using weight vector $\boldsymbol{w}$. We int oúces a rank acceptability index to evaluate each alternative's acceptability according to the calculated utivity results. A ranking function is defined to determine the ranking sequences from the best (1) to the worst (?n) as (Lahdelma and Salminen, 2001):

$$
\operatorname{rank}\left(\xi_{i}, \boldsymbol{w}\right)=1+\sum_{k} \rho\left[u\left(\xi_{k}, \boldsymbol{w}\right)>u\left(\xi_{i}, \boldsymbol{w}\right)\right](1)
$$

where $\rho($ true $)=1$ and $\rho($ false $)=0, \xi$ is used to stand for criteria PVs having a stochastic distribution of $f_{X}(\boldsymbol{\xi})$, similarly $\boldsymbol{w}$ has a stochastic distribution of $f_{W}\left(\boldsymbol{w}\right.$. Then we can define the favorable rank weights, $W_{i}^{r}(\boldsymbol{\xi})$ :

$$
W_{i}^{r}(\boldsymbol{\xi})=\left\{\boldsymbol{w} \in W: \operatorname{rank}\left(\xi_{i}, \boldsymbol{w}\right)=r\right\} \text {, where } W=\left\{\boldsymbol{w} \in R^{n}: w_{j} \geq 0, \sum_{j=1}^{n} w_{j}=1\right\}
$$

If a weight vector $\boldsymbol{w} \in W_{i}^{r}(\boldsymbol{\xi})$, then it makes that alternative $x_{i}$ obtains rank $r$. Based on this, the rank acceptability index, $b_{i}^{r}$ can bedefined as:

$$
b_{i}^{r}=\int_{X} f_{X}(\xi) \int_{W_{i} / \xi} f_{W}(w) d w d \xi(3)
$$

In fact, $b_{i}^{r}$ indicates all the different valuations that make alternative $x_{i}$ rank $r$. It is not possible to calculate $b_{i}^{r}$ directily from the integral formula, but it can be calculated by using the Monte Carlo simulation. From this print of view, rank acceptability also can be explained as the share (\%) of Monte Carlo simulations that make alternative $x_{i}$ rank $r$. SMAA-2 uses a holistic acceptability index shown in Eq.(4) to consider contributions of all ranks, which is an obvious improvement compared to the original SMAA model (Lahdelma et al., 1998).

$$
a_{i}^{h}=\sum_{r=1}^{m} \alpha b_{i}^{r}
$$


where $\alpha_{r}$ are the meta-weights, which means the contribution of each rank acceptability index to the holistic evaluation. In general, first ranks contribute most and the worst ranks contribute least to the holistic acceptability index.

The central weight vector, $w_{i}{ }^{c}$, can be expressed in Eq. (5).

$$
\boldsymbol{w}_{i}^{c}=\frac{\int_{X} f_{X}(\boldsymbol{\xi}) \int_{W_{i}^{1}(\xi)} f_{W}(\boldsymbol{w}) \boldsymbol{w} d \boldsymbol{w} d \boldsymbol{\xi}}{b_{i}^{1}}(5)
$$

The central weight vector can be deemed as the best single representation of the preference from a DM supporting $x_{i} \cdot w_{i}^{c}$ is actually the average value of the weight vectors favoring alternative $i$

The confidence factor, $p_{i}^{c}$, is the probability that $x_{i}$ ranks first when its central weight vector is used. That is to say, only the first rank acceptability $b_{i}{ }^{1}$ has the confidence factor, which can be defined as:

$$
p_{i}^{c}=\int_{\xi \in X: \operatorname{rank}\left(\xi, w_{i}^{c}\right)=\mathbf{1}} f_{X}(\xi) d \xi(6)
$$

The confidence factor is used to evaluate whether the criteria $\mathrm{FV}$ s are accurate to differentiate alternatives using the central weight vectors.

In addition, we also can calculate the confidence factors for different alternatives using each others' central weight vectors, which are called cross confidence factors. The cross confidence factor for alternative $x_{i}$ with respect to target alternative $x_{k}$ s derined as:

$$
p_{i k}^{c}=\int_{\xi \in X, b_{k}^{1} \neq 0: w_{k}^{c} \in W_{i}^{1}(\xi)} f_{X}(\xi) a^{1} \xi(7)
$$

The cross confidence factor can reach better discrimination capability, by measuring the probability that $x_{i}$ obtain the first rank when the central weight vector of $x_{k}$ is used. Nonzero cross confidence factors means that the alternative $x_{i}$ will compete for the first rank with the central weight vector of alternative $x_{k}$ and the competence extent can also be determined. Note that the cross confidence factor $p_{i i}{ }^{c}$ is exactly the confidence factor $p_{i}^{c}$. In all, rank acceptability indices, holistic acceptability indices, central weight vectors and confidence factors are used to facilitate the evaluation of DH systems.

\subsection{The SMAA-O model}


The SMAA-O model was developed for problems with ordinal criteria (Lahdelma et al., 2003). It uses rank level numbers, $r_{j}=1,2, \ldots, j^{\max }$, to sort the alternatives in terms of each criterion. It is clear that 1 is the best and $j^{\max }$ is the worst rank level. In reality, two or more alternatives may be deemed equally good, so that $j^{\text {max }} \leq m$. In SMAA-O, the ordinal measurements are mapped into the cardinal values. All consistent mapings between the ordinal scales and cardinal values are considered. Monte Carlo simulations are used to generate random cardinal values corresponding to the ordinal values. Let $\gamma_{j}$ is the cardinal values for rank levels, $r_{j}$, then the mapping (David and Nagaraja, 2003) is:

$$
\gamma_{j}=v_{j}\left(r_{j}\right)(8)
$$

The lower the rank is the better for an alternative, therefore, $v(\bullet$, shoula be a monotone decreasing mapping. In this study, $\gamma_{j}$ is in the interval $[0,1]$. The mapping process is shown in Fig. 2 . The sum of the scale intervals can be expressed as:

$$
\sum_{r=1}^{j^{m a x}-1} \Delta \gamma_{j, r}=\sum_{r=1}^{j^{m a x}-1}\left(\gamma_{j, r+1}-\gamma_{j, r}\right)=1(9)
$$

Therefore the problem becomes to simulate ail cardinal scales that satisfy,

$$
\Gamma_{j}=\left\{\Delta \gamma_{j} \in R^{j^{m a x}-1}: \Delta \gamma_{j, r}>0, \sum_{r=1}^{j^{m a x}-1} \Delta \gamma_{j, r}=1,(10)\right.
$$

The valid interval space will expand as the mapping numbers $(K)$ increases; this is illustrated in Fig. 3 for $j^{\max }=m=11$. It is clear that the mapping from ordinal scales to cardinal values can cover more and more interval space with more iterations.

If there is 110 inforination about the scale intervals, then we can use a uniform distribution in the simulation. During the simulation, $j^{\max } \rightarrow$ distinct random numbers will be generated according to the uniform distribution in $[0,1]$ and be sorted in decreasing order so that $1=\gamma_{j}, 1>\gamma_{j}, 2>\ldots>\gamma_{j} j^{\max }=0$. SMAA-O also tras rank acceptability indices, the central weight vectors, and the confidence factors.

\subsection{Feasible weight space (FWS)}


A weight vector is only one point in the weight space, but only one point is not a good representation for the preferences of a group of DMs (Liu et al., 2017) in real life. This is why we propose the Feasible Weight Space (FWS) concept. FWS is a part of the general weight space, which assumes random variables with certain probability distributions in the feasible sub-space. Therefore, weight vectors are taken with certain probability distributions from the FWS in the Monte Carlo simulation. For example, in a three criteria problem, the general weight space can be shown as a plane in Fig. 4(a); but a possible FWS with interval constraints is demonstrated as a polygon shaded area shown in Fig. 4(b). This FWS can be expresses as:

$$
W=\left\{\boldsymbol{w} \in R^{n}: w_{j} \geq 0, w_{j}^{\min } \leq w_{j} \leq w_{j}^{\max }, \sum_{j=1}^{n} w_{j}=1\right\}
$$

FWS identifies a more accurate sub-space than the general weight space. For group decision making, it is necessary to obtain this sub-space to cover all DMs' preferences. We can also set an interval for each criterion based on the calculated weight vector to represent the uncertaincies.

\subsection{Handling the uncertainties}

A certain probability distribution around the expected values of the criteria PVs is used to express the uncertainties. The most popular distributions are uniform and normal distributions (Lahdelma et al., 1998) and the former one is used in this study The SMAA-O model already takes into account of the uncertainties when simulating the mapping processes, therefore we only focus on how to treat the uncertainties in weighting by taking a 3-criterion example. However, the same technique can be used in higher dimensions.

If there is no veighting information in the extreme cases, a uniform distribution is assumed. In 3-criterion case, the FW $\$$ is a $(n-1)$-dimensional Simplex. Fig. 5 shows the projection onto $w_{1}-w_{2}$ plane for the FWS in Fig. 4, respectively.

The weight intervals $w_{j} \in\left[w_{j}^{\text {min }}, w_{j}^{\text {max }}\right]$ may come from direct preference statements of the DMs or from judgments matrices [20]. The intervals can be obtained by restricting the uniform weight distribution with linear inequality constraints.

\section{Results and discussion}




\subsection{The case of seven DH systems in a city of north China}

In a north city of China (Baoding), seven DH alternatives are planned for a same DH system, which has a floor heating area of $251,746 \mathrm{~m} 2$ with a design heat load of $16.6 \mathrm{MW}$. Space heating season is 120 days a year and the average outdoor air temperature is $-1.6^{\circ} \mathrm{C}$. The design indoor and outdoor air temperatures are $18^{\circ} \mathrm{C}$ and $-9^{\circ} \mathrm{C}$, respectively. Assume that all DH systems provide the same DH capacity for this area, and then the properties of economy, environment and energy for the seven DH systems are shown in Table I (Wei et al., 2010).

There are both quantitative and qualitative criteria in Table 1. The uncertainiv of economic indices is assumed 10\% (Hokkanen et al., 2000); because the emission data is with large flexibility, so that an uncertainty of $\pm 20 \%$ is used for the environmental criteria. However for the qualitative (ordinal) energy criteria, the uncertainty will be handed by SMAA-O automatically using the Monte Carlo simulation. The uncertainty in weighting is considered by an FWS obtained by giving $\pm 50 \%$ linear constraints using uniform distribution (Wang et al., 2015) to each criterion based on the weight vector elicited by Wei et al. (2010). The FWS can cover more possible preference information, indicated in Fig. 6.

\subsection{Results of stochastic multicriteria arceptedbility analysis}

In this study, the criteria PV's of the seven DH systems in Table 1 are normalized firstly. Then we use 100,000 Monte Carlo iterations to calculate the statistic variables in the simulation (Wang et al., 2016), which will result in erroi limits smaller than 0.01 (Tervonen and Lahdelma, 2007). The confidence factors, holistic acceptability and rank acceptability indices are shown in Table 2. All rank acceptability indices and average utilities of each DH system are also illustrated graphically in Fig. 7. Here the average utility is defined as an the central-weighted average utility function value based on the criteria PVs. Central weight vectors and the cross confidence factors are shown in Fig. 8 and Table 3. Note that there is no central weight vector for a DH systems having zero confidence factors.

According to Table 2, coal- and oil-fired HOBs can be rejected from the most qualified DH systems, because their confidence factors are zero. This means that they never obtain the first rank even considering 
the uncertainties. Similarly, solar energy HP is currently not a good choice for DH because of its nearly zero confidence factor and very low holistic acceptability index. GSHP has a $4.87 \%$ confidence factor, which are also deemed so small to be the best alternative, but it still can be a compromise DH system especially a weight vector close to its central weights is used. However, coal-fired CHP has a high confidence factor of 75.75\%, followed by gas-fired HOB (57.43\%) and WSHP (18.92\%). In addition, the first rank asceptability index of coal-fired CHP is $51.2 \%$, which already dominate the other DH systems. Nevertheless, the second rank acceptability index is $24.9 \%$ and zero for worst ranks, which means that coal-fired CHY is the most preferred DH technology in the study area with the design DH load (16.6MW) considering uncertainties. Gasfired HOB and WSHP also can be the compromise DH systems if their central weight vectors are used.

As can be seen from Fig. 7, coal-fired CHP favors criteria of total cost, but if the DMs are not emphasizing the total cost, then gas-fired HOB is very suitabie for DH in this area. This is also justified by the SMAA result that gas-fired HOB competes greatly with the three HP systems and has a good chance to be the best alternative even three HP systems' central weights are finally used. This can be justified by Table 3 , e.g. when the central weight of solar HP system is finaily chosen, the cross confidence factor of Gas-HOB is far bigger than the confidence factor itself $(0.021 \%)$ for solar HP. In fact, it is the smallest confidence factor, because Gas-HOB, WSHP, GSHP, Coal-CHIP all have bigger cross confidence factors when solar HP is the target alternative. This indicates that selar HP will not be the most preferred or compromise alternative. The situations are similar when other two HPs' central weights are used, because Gas-HOB will dominate the WSHP and GSHP. In sther words, HPs only have small chances to be the best alternative even weights are close to their central weights (close to the central weight of gas-HOB too), as shown in Fig. 8.

The ranking of the DH systems based on the average utility can be found and Fig. 9. We found that the first three rankings are the same with the result given by Wei et al. (2010), where they use a fuzzy comprehensive evaluation method to solve the same problem. They considered the uncertainties by giving the preference priority to economics, environment and energy technology respectively. This method was fine but still can be improved by using the proposed FWS with uniform distribution and Monte Carlo simulation. In 
our method, GSHP, solar energy HP and oil-fired HOB have the same ranking as the fuzzy comprehensive evaluation method. The only difference is that the coal-fired HOB rank 4 in their conclusion but it is apparently the worst alternative in our study. The reason is that if total cost is emphasized then coal-fired $\mathrm{HOB}$ is dominated by coal-fired CHP, otherwise it is dominated by other DH technologies having less environmental impacts.

In our method, if the above statistic variables are still not enough to differentiate the aiternatives, then pairwise winning indices can be defined using the existing statistic variables. Namely, the pairvise winning index $c_{i j}$ is the probability for alternative $i$ to score better than alternative $j$ considering tre uncertainty in the preference statements. It can be calculated by the times that alternative $i$ is better than $j$ divided by the total Monte Carlo simulation iterations.

A full ranking sequence of all DH systems can also be obtained according to the simulation results. However, this may lead to some kind of misunderstanding and thus not encouraged. DMs may believe that the alternative with largest utilities dominates all the others, disregarding the fact that ranking sequence is subject to uncertainties in weighting. Therefore, SMAA method is used to help understand the evaluation by using the rank acceptability indices and the confidence factors. SMAA plus FWS can help determine what kind of weight information will faror what kind of alternative taking into account of the probability. This makes the combination of SMAA and FWS more reliable in the multicriteria evaluation. Therefore, the proposed method can also be used in other MCDA problems.

\section{Conclusions}

It is a typical malticriteria decision making problem to choose a suitable district heating (DH) alternative for a specific DH area. This problem can be addressed from economics, environment and energy (3E) points of view, in which the criteria performance values (PVs) and weighting are characterized by uncertain or imprecise information. In this paper, we develop a novel and efficient multicriteria evaluation method, which can simultaneously consider the uncertainties in the criteria PVs and weighting for the DH systems. Specifically, the uncertainties in criteria PVs are treated using uniform distribution function within the 
uncertainty range of each criterion, and uncertainties in weighting are addressed by the Monte Carlo simulation in the stochastic multicriteria analysis (SMAA) model. SMAA calculates the statistic variables of rank acceptability indices, confidence factors, central weight vectors and cross confidence factors, which can help DMs understand what kind of weight information will favor what kind of alternatives and to what extent.

The method was successfully demonstrated in a north city of China, and compared with a previous study for the same problem using fuzzy comprehensive evaluation method. The first three DH alternatives of the both methods are the same, but coal-fired heat only boiler (HOB) ranks 4 in the fuzzy comprehensive evaluation method, while it is apparently the worst in our study. The reason is that if tora cost is emphasized then coal-fired HOB is dominated by coal-fired CHP, otherwise it is dominated by other DH technologies having less environmental impacts. Therefore, SMAA plus FWS can make clear that what kind of weight information will favor what kind of alternative taking into account of the probability distribution. This makes our method more reliable in the multicriteria evaluation and can aiss be extended for other MCDA problems. SMAA also helps reveal the inefficient alternatives og oil- and coal-fired HOBs, because they are dominated by other DH technologies even considering their central weight vectors and the uncertainties. In addition, a full ranking of the alternatives is not recommended in this study, because it will very easily lead to a misunderstanding that the best alcernative dominates all the others in any situation. On the contrary, we should bear in mind that any ranking is subject to uncertainties that should be well considered.

\section{Acknowledgement}

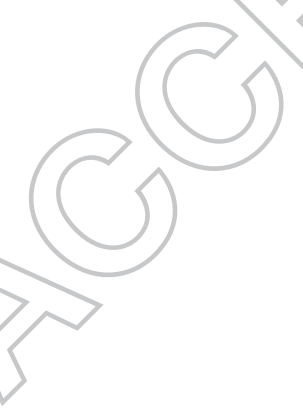




\section{References}

Cao, Y., G.M. Chen, and W.F. Xu. 2002. Optimization of heating modes for medium and large cities. Journal of HVAC 32(1):7-10.

Chao, J.L. 2014. Cool Roofs in China Can Save Energy and Reduce Emissions - Berkeley Lab-Ied study confirms efficacy of cool roofs in parts of China. http://newscenter.lbl.gov/2014/08/27/cool-roofs-inchina-can-save-energy-and-reduce-emissions/, August 27, 2014.

David, H.A., and H.N. Nagaraja. 2003. Order Statistics. Wiley Series in Probability and Statistics.

Durbach, I.N., and T.J. Stewart. 2012. Modeling uncertainty in multi-criteria decision analysis. European Journal of Operational Research 223:1-14.

Gang, W.J., S.W. Wang, C.C. Yan, and F. Xiao. 2015. Robust optimai design of building cooling systems concerning uncertainties using mini-max regret theory. Science and Technology for Built Environment, 21(6):789-799.

Ghafghazi, S., T. Sowlati, S. Sokhansanj, and S. Mielin 2910. A multicriteria approach to evaluate district heating system options. Applied Energy 87(4): 1134--1140.

Hokkanen, J., R. Lahdelma, and P. Saiminen. 2000. Multicriteria decision support in a technology competition for cleaning poilyted sojl in Helsinki. Journal of Environmental Management 60:339-348.

Huang, J. 2011. Comprenensive evaluation for the setup of peak heating using gas fired boiler. Master Thesis, Beijing J riversity of Civil Engineering and Architecture, Beijing, China.

Jiang, W., T.A. Reddy, and P. Gurian. 2007. General Methodology Combining Engineering Optimization of Primairy HVAC \& R Plants with Decision Analysis Methods-Part II: Uncertainty and Decision Analysis. HVAC\&R Rsearch 13(1):119-140.

Konu, Y., S. Rinne, V. Olkkonena, R. Lahdelma, and P. Salminen. 2015. Multicriteria evaluation of heating choices for a new sustainable residential area. Energy and Buildings 93:169-179.

Lahdelma, R., P. Salminen, A. Simonen, and J. Hokkanen. 2001. Choosing a reparation method for a landfill using the SMAA-O multicriteria method. In Multiple Criteria Decision Making in the New Millennium, 
Lecture Notes in Economics and Mathematical Systems, 2001, 507, pages 380-389. Springer-Verlag, Berlin.

Lahdelma, R., and P. Salminen. 2001. SMAA-2: Stochastic multicriteria acceptability analysis for group decision making. Operations Research 49(3):444-454.

Lahdelma, R., J. Hokkanen, and P. Salminen. 1998. SMAA—stochastic multiobjective acceptability ahalysis. European Journal of Operational Research 106(1):137-143.

Lahdelma, R., K. Miettinen, and P. Salminen. 2003. Ordinal criteria in stochastic multicriteria acceptability analysis (SMAA). European Journal of Operational Research 147:117-127.

Li, M., H.L. Mu, N. Li, and B.Y. Ma. 2016. Optimal design and operation strategy for integrated evaluation of CCHP (combined cooling heating and power) system. Energy $90 \cdot 202--220$.

Lin, Z.H. 2002. Influences of the energy policy reformation of our country on developments of industrial boilers. Industrial Boiler (3): 4-7.

Liu, C., G.L. Tang, and P.D. Liu. 2017. An approach io mulyicriteria group decision-making with unknown weight information based on Pythagorean fuzzy uncertain linguistic aggregation operators. Mathematical problems in Engineering, Article ID 6414020, https://doi.org/10.1155/2017/6414020.

Shan, K., S.W. Wang, F. Xiao, and Y.J. Sun. 2013. Sensitivity and uncertainty analysis of cooling water control strategies. HVAC\&R Rsearch 19(4):435-443.

Soltero, V.M., R. Chacartegu, C. Ortiz, and R. Velázquez. 2016. Evaluation of the potential of natural gas district heating cogeneration in Spain as a tool for decarbonisation of the economy. Energy 115: 15131532.

Tervonen, T., and J.R. Figueira. A survey on stochastic multicriteria acceptability analysis methods. Journal of Muili-Criteria Decision Analysis 15(1-2):1-14.

Tervonen, T., and R. Lahdelma. 2007. Implementing stochastic multicriteria acceptability analysis. European Journal of Operational Research 178(2):500-513. 
Troldborg, M., S. Heslop, and R.L. Hough. 2014. Assessing the sustainability of renewable energy technologies using multi-criteria analysis: Suitability of approach for national-scale assessments and associated uncertainties. Renewable and sustainable energy reviews 39:1173-1184.

Tsinghua University building energy research center. 2014. Annual Report on China Building Energy Efficiency. China Building Industry Press.

Tylock, S.M., T.P. Seager, J. Snell, E.R. Bennett, and D. Sweet. 2012. Energy management under policy and technology uncertainty. Energy Policy 47:156-163.

Wang, H.C. 2013. Development and application of a multicriteria decision support framework for planning or retrofitting district heating systems. Aalto University publication series Dsetcral dissertations.

Wang, H.C., Z.G. Zhou, W.L. Jiao, P. Wang, and R. Lahdelma. 2016. Stochastic multicriteria evaluation of district heating systems considering the uncertainties. In proceedings of the 9th International Symposium on Heating, Ventilation and Air Conditioning (ISHVAC)-The srd International Conference on Building Energy and Environment (COBEE), July 12 -15, Tianjin, China.

Wang, L.P., and P. Haves. 2014. Monte Carlo analysis of the effect of uncertainties on model-based HVAC fault detection and diagnostics. HVAC\&R Research 20(6):616-627.

Wang, H.C., W.L. Jiao, R. LahdeIna, C.Z. Zhu, and P.H. Zou. 2015. Stochastic Multicriteria Acceptability Analysis for Evaluation of Combined Heat and Power Units. Energies 8(1), 59-78.

Wei, B., S.L. Wang, and I. Li. 2010. Fuzzy comprehensive evaluation of district heating systems. Energy Policy 38:5947-5955.

Zarghami, M., and F. Szidarovszky. Stochastic-fuzzy multi criteria decision making for robust water resources management. Environmental research and risk assessment 23:329-339. 
Table 1. Properties of the seven DH systems.

\begin{tabular}{|c|c|c|c|c|c|c|c|}
\hline Criteria & $\begin{array}{l}\text { Coal-fired } \\
\text { CHP }\end{array}$ & Gas-fired & Oil-fired & Coal-fired & Solar energy HP & WSHP & GSHP \\
\hline & & HOB & HOB & HOB & & & \\
\hline Total cost per floor area $\left(¥ / \mathrm{m}^{2}\right)^{\mathrm{a}}$ & 26.96 & 46.85 & 78.40 & 32.19 & 67.88 & 54.95 & 62.27 \\
\hline $\mathrm{NO}_{\mathrm{x}}\left(\mathrm{g} / \mathrm{m}^{2}\right)^{\mathrm{b}}$ & 588.0 & 92.9 & 116.0 & 840.0 & 91.9 & 78.4 & 87.8 \\
\hline $\mathrm{SO}_{2}\left(\mathrm{~g} / \mathrm{m}^{2}\right)^{\mathrm{b}}$ & 179.0 & 94.0 & 127.0 & 255.7 & 162.0 & 138.1 & 154.8 \\
\hline $\mathrm{CO}\left(\mathrm{g} / \mathrm{m}^{2}\right)^{\mathrm{b}}$ & 8.9 & 1.9 & 3.5 & 40.9 & 1.14 & 0.85 & 0.95 \\
\hline $\mathrm{CO}_{2}\left(\mathrm{~g} / \mathrm{m}^{2}\right)^{\mathrm{b}}$ & 40871 & 31920 & 40314 & 58224 & 24054 & 20504 & 22985 \\
\hline Other $\left(\mathrm{g} / \mathrm{m}^{2}\right)^{\mathrm{b}}$ & 73.9 & 27.1 & 18.1 & 105.6 & 22.2 & 19.0 & 21.3 \\
\hline Technical merits $^{c}$ & Good & Good & Good & Little bad & Neutral & Good & Good \\
\hline Mentality effect $^{c}$ & Better & Good & Good & bad & Good & Good & Good \\
\hline Heating charge $^{c}$ & Better & Neutral & $\mathrm{Bad}$ & Better & $\mathrm{Bad}$ & Little ba & Neutral \\
\hline
\end{tabular}

a) It includes the annuity of initial investment and annual operating cost, ¥ means Chinese currency RMB yuan;

b) Emission is calculated based on the floor heating area;

c) These three properties are deemed as qualitative (ordinal) criteria. 
Table 2. Confidence factors $\left(\boldsymbol{p}^{\boldsymbol{c}}\right)$, holistic $\left(\boldsymbol{a}^{\boldsymbol{h}}\right)$ and rank acceptability indices $\left(\boldsymbol{b}^{\boldsymbol{r}}\right)$ in percentage.

\begin{tabular}{|l|l|l|l|l|l|l|l|l|l|}
\hline DH system & $\boldsymbol{p}^{\boldsymbol{c}}$ & $\boldsymbol{a}^{\boldsymbol{h}}$ & $\boldsymbol{b}^{\mathbf{1}}$ & $\boldsymbol{b}^{\mathbf{2}}$ & $\boldsymbol{b}^{\mathbf{3}}$ & $\boldsymbol{b}^{\mathbf{4}}$ & $\boldsymbol{b}^{\mathbf{5}}$ & $\boldsymbol{b}^{\mathbf{6}}$ & $\boldsymbol{b}^{\mathbf{7}}$ \\
\hline Coal-fired CHP & 75.75 & 73.7 & 51.2 & 24.9 & 13.3 & 10.0 & 0.5 & 0 & 0 \\
\hline Gas-fired HOB & 57.43 & 72.5 & 39.2 & 48.8 & 10.8 & 1.3 & 0 & 0 & 0 \\
\hline WSHP & 18.92 & 45.7 & 8.3 & 20.3 & 54.2 & 17.1 & 0.1 & 0 & 0 \\
\hline GSHP & 4.87 & 31.0 & 1.4 & 5.9 & 21.6 & 69.5 & 1.7 & 0 & 0 \\
\hline Solar energy HP & 0.02 & 12.5 & 0.001 & 0 & 0.1 & 1.5 & 68.5 & 27.7 & 2.3 \\
\hline Oil-fired HOB & 0 & 6.6 & 0 & 0 & 0 & 0.1 & 18.6 & 55.6 & 25.7 \\
\hline Coal-fired HOB & 0 & 2.9 & 0 & 0 & 0.1 & 0.6 & 10.8 & 16.6 \\
\hline
\end{tabular}


Table 3. Cross confidence factors (\%), confidence factors are in bold, and the biggest cross confidence factors are underlined.

\begin{tabular}{|l|l|l|l|l|l|l|l|l|}
\hline Alt. & Coal-CHP & Gas-HOB & Oil-HOB & Coal-HOB & Solar-HP & WSHP & GSHP & Sum \\
\hline Coal-CHP & $\underline{\mathbf{7 5 . 7 5 2}}$ & 23.187 & - & - & 0 & 1.048 & 0.013 & 100 \\
\hline Gas-HOB & 31.994 & $\underline{\mathbf{5 7 . 4 3 2}}$ & - & - & 0 & 9.806 & 0.768 & 100 \\
\hline Oil-HOB & - & - & - & - & - & - & - & \\
\hline Coal-HOB & - & - & - & - & - & - & - & \\
\hline Solar-HP & 3.225 & $\underline{4.57}$ & - & - & $\mathbf{0 . 0 2 1}$ & 32.316 & 19.868 & 100 \\
\hline WSHP & 15.445 & $\underline{63.084}$ & - & - & 0 & $\mathbf{1 8 . 9 1 0}$ & 2555 & 100 \\
\hline GSHP & 9.598 & $\underline{62.412}$ & - & - & 0 & 23.118 & 4.872 & 100 \\
\hline
\end{tabular}




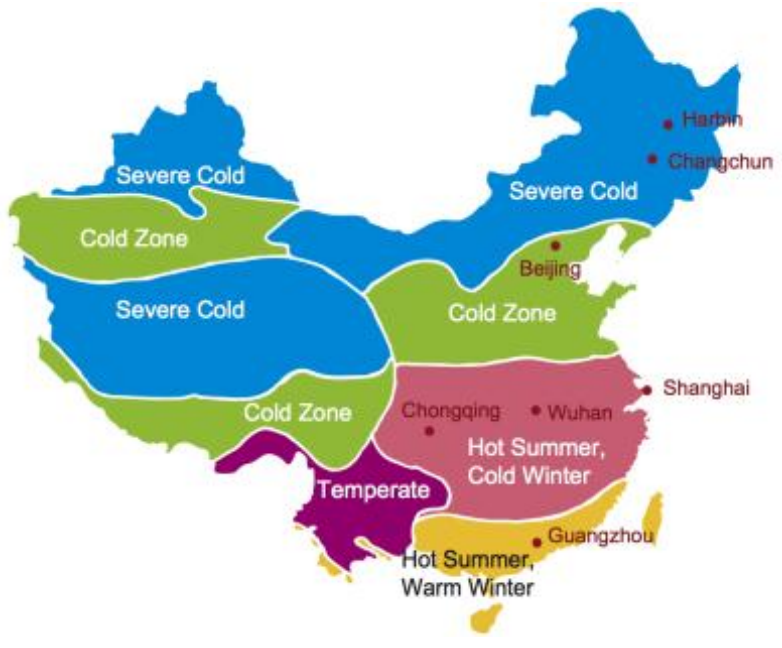

Fig. 1. Building climate zones in China (Chao, 2014). 


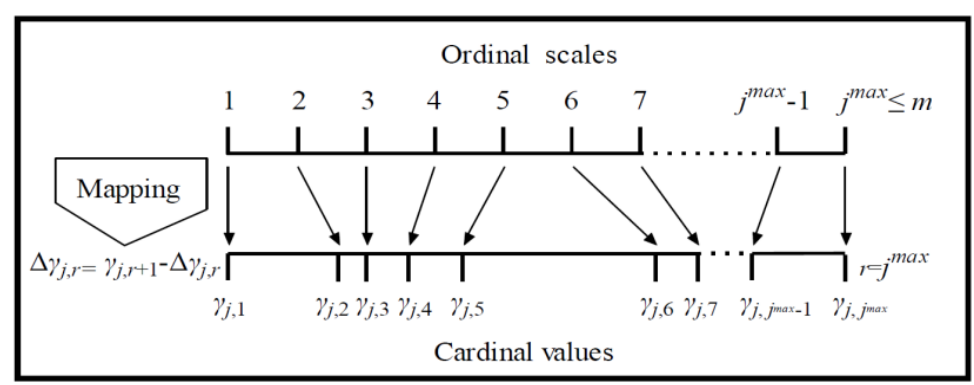

Fig. 2. The mapping from ordinal scales to cardinal values in SMAA-O. 


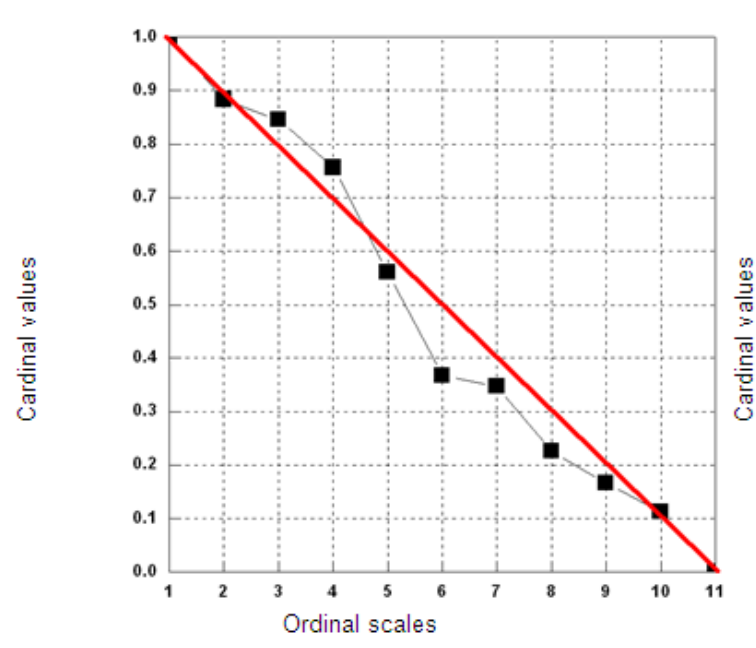

(a) $K=1$

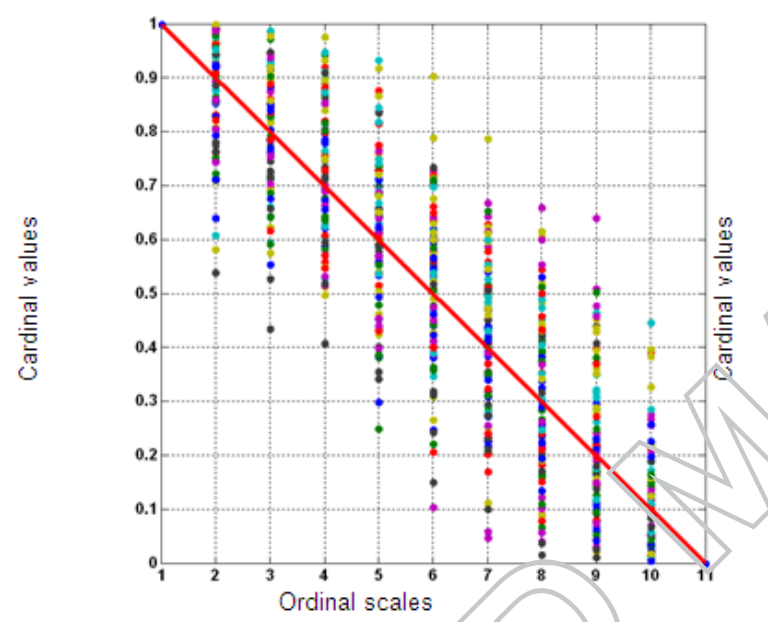

(c) $Y=500$

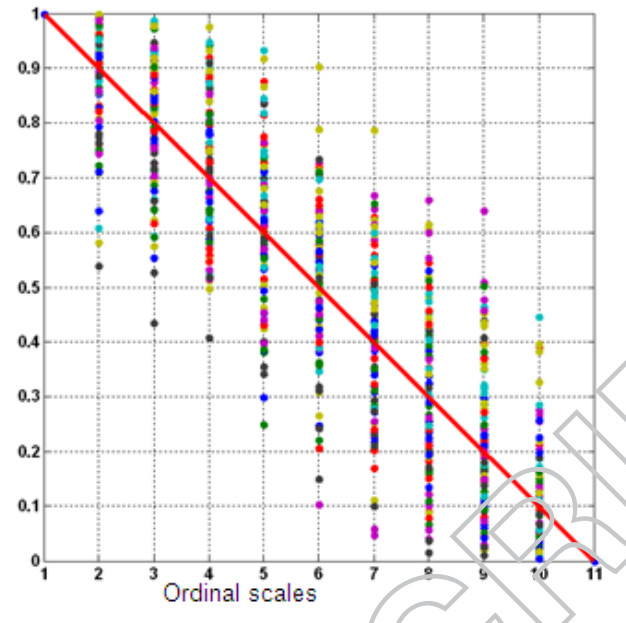

(b) $K=100$

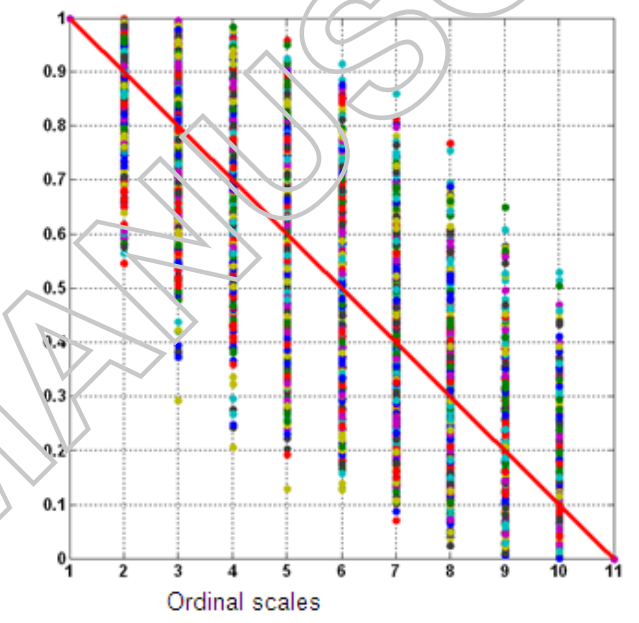

(d) $K=1000$

Fig. 3. Variation of $\Gamma_{j}$ mapping ordinal scales onto cardinal values with simulation iterations $K$ from 1 to 1000 in SMAA-O when $j^{\max }=m=11$ (the straight lines stand for linear mapping) (wang, 2013). 


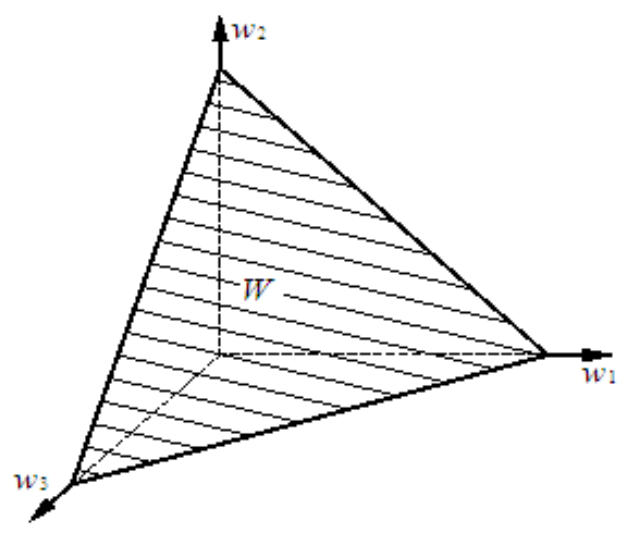

(a) a general $3 \mathrm{D}$ weight space

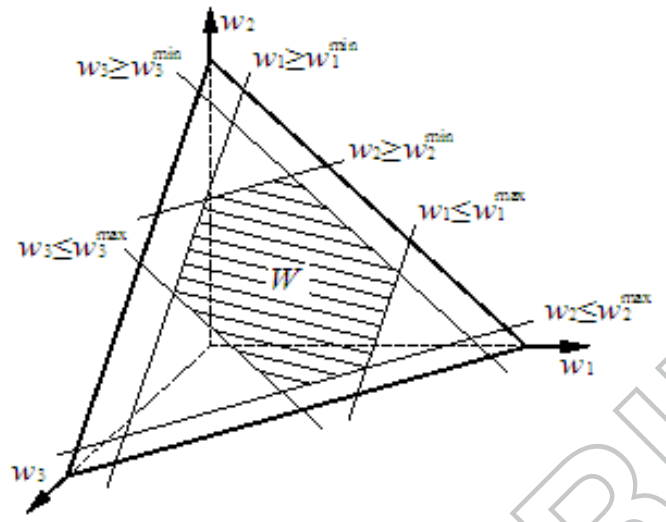

(b) FWS with interval constraints in $3 \mathrm{D}$ weight space

Fig. 4. A deterministic weight vector A in a general weight space of a three criteria case and an FWS with interval constraints on each criterion. 


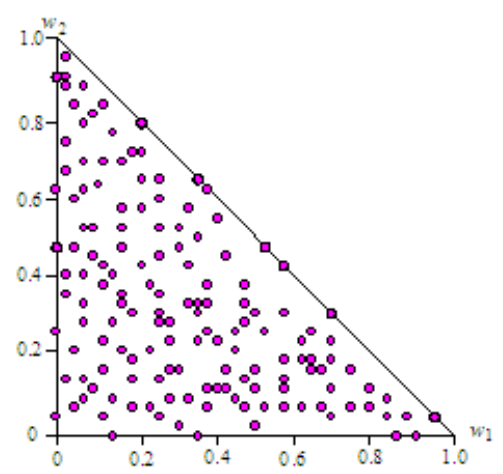

(a) a general 3D weight ppace

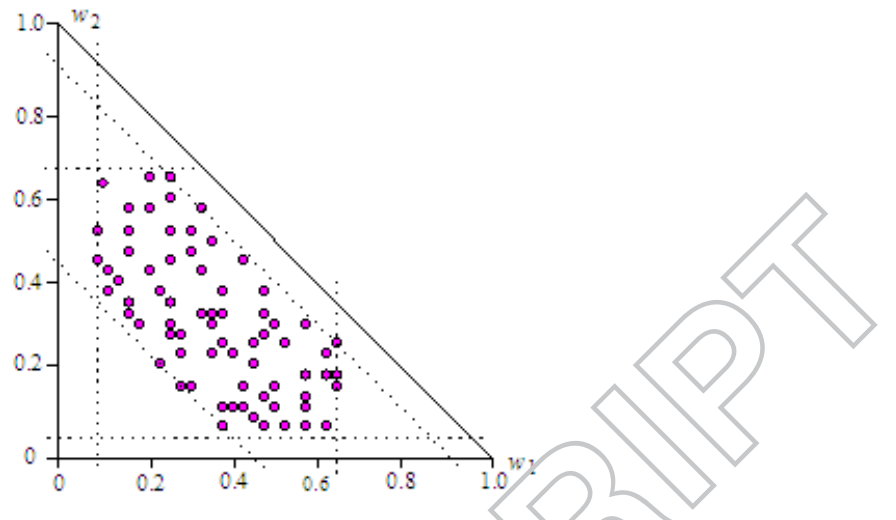

(b) FWS with interval constraints in $3 \mathrm{I}$ weight space

Fig. 5. Projection onto $\mathrm{w}_{1}-\mathrm{w}_{2}$ plane of the FWS shown in Fig. 4. 


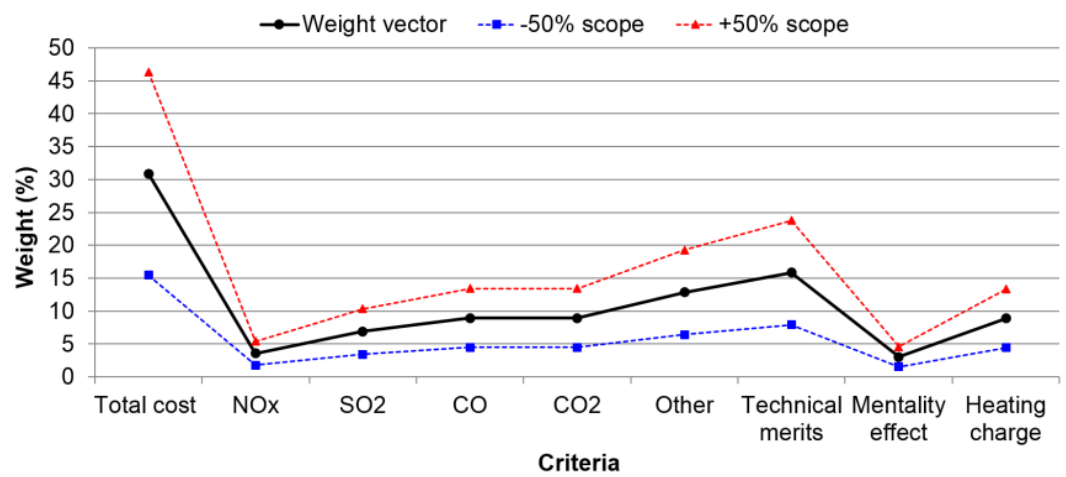

Fig. 6. The FWS with $\pm 50 \%$ interval constraints using uniform distribution on eacin criterion for evaluation of the DH systems. 


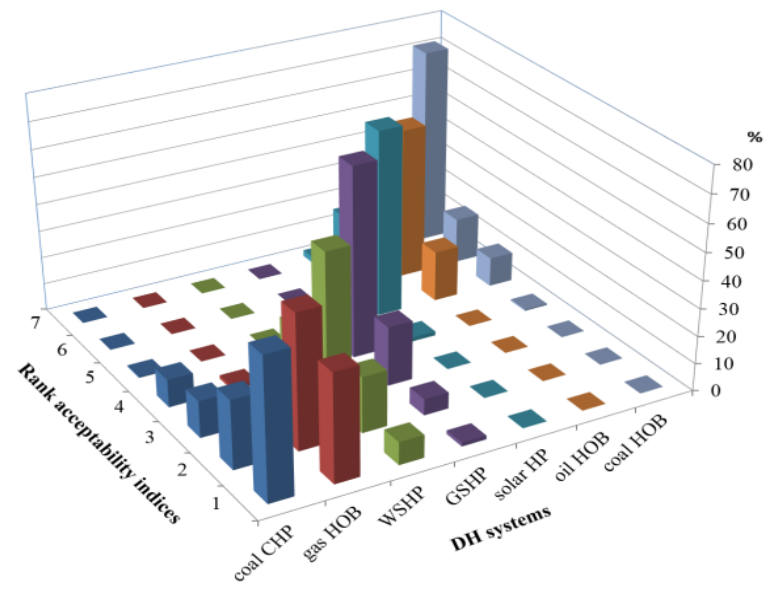

Fig. 7. Rank acceptability indices $\left(b^{r}\right)$ of the seven DH systems. 


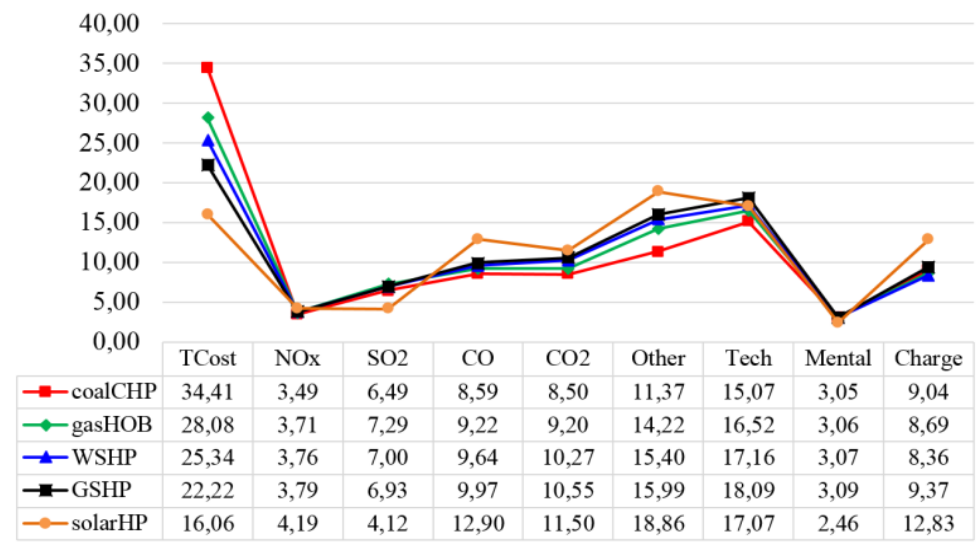

Fig. 8. Central weights $\left(w^{c}\right)$ favoring different DH systems. 


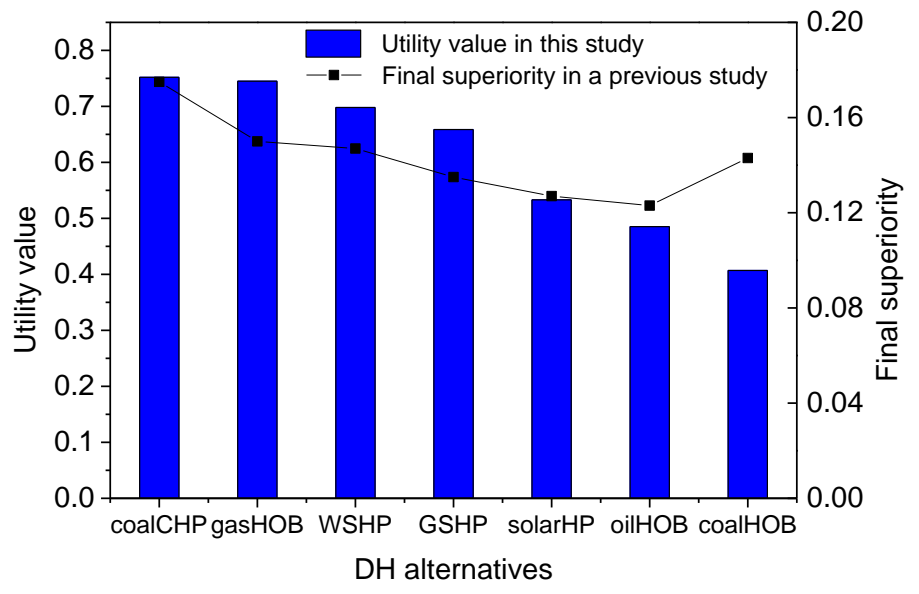

Fig. 9. Comparison between the utility value in this study and the final superiority in Wei et al. (2010). 